\title{
Triamacinolone acetonide versus bevacizumab in treatment of neovascular age related macular degeneration
}

\author{
Mona Abdel Kader* \\ Mansoura Ophthalmic Center, Faculty of Medicine, Mansoura University, Egypt
}

\begin{abstract}
Purpose: To evaluate the effects of intravitreal triamacinolone acetonide (IVTA) and bevacizumab injection on visual acuity, electrophysiologic response and foveal thickness of patients with neovascular age related macular degeneration $(\mathrm{CNVs})$.

Methods: The study included three groups. Group 1 included fifty eyes (50 patients) with progressive occult or predominately occult subfoveal choroidal neovascularization treated with intravitreal injection of trimacinolone acetonide. Group 2 included another fifty eyes (50 patients) with progressive macular degeneration of occult or predominately occult subfoveal choroidal neovascularization treated with intravitreal bevacizumab. The patients are followed up every month by biomicroscopy, optical coherence tomography (OCT), photography, flourescein angiography, Ganzfeld full field electroretinogram (F-ERG), multifocal electroretinogram (MF-ERG) and determination of best corrected visual acuity (BCVA). Group 3 (control group) included 50 eyes (50 patients) with neovascular age related macular degeneration who did not receive treatment for macular degeneration.

Results: Apparent improvement of morphological and functional characteristics were observed in 40/50 eyes after one month after first injection in group 1, and in $45 / 50$ in group 2 . The mean \pm SD visual acuity improved significantly $(\mathrm{p}=0.003)$ from $(0.12 \pm 0.19$ to $0.35 \pm 0.25$ ) in group 1 and from $0.13 \pm 0.2$ to $0.40 \pm 0.28$ in group 2. Visual acuity was highest $1-2$ month after intravitreal injection. Central macular thickness decreased from $325 \pm 50 \mu \mathrm{m}$ to $275 \pm 40 \mu \mathrm{m}$ at one month after first injection in group 1 and decreased from $320 \pm 53 \mu \mathrm{m}$ to $255 \pm 41 \mu \mathrm{m}$ in group 2 while in control group, there is statistically insignificant increase of the central thickness. The average amplitude of central macular ring of MFERG was improved from $25.5 \pm 5.8 \mathrm{nv}$ to $31 \pm 8.9 \mathrm{nv}$ in group 1 and from $26.6 \pm 6.1 \mathrm{nv}$ to $33 \pm 9.9 \mathrm{nv}$ in group 2, while no changes in F-ERG response. Intraocular pressure increased significantly ( $\mathrm{p}=0.009)$ from $14 \pm 2.5 \mathrm{mmHg}$ to maximal $23 \pm 7.6 \mathrm{mmHg}$ in group 1. Intraocular pressure decreased significantly $(\mathrm{p}=0.006)$ to $16 \pm 2 \mathrm{mmHg}$ at the end of follow up while in group 2, there was no increase in intraocular pressure. No other serious drug related adverse events (endophthalmitis, retinal detachment, cataract or proliferative vitreoretinopathy) observed during the course of the study in groups 1,2. In control group, visual acuity, central foveal thickness and function did not change significantly during follow up period ( $\mathrm{p}=0.6, \mathrm{p}=0.4, \mathrm{p}=0.1 \mathrm{respectively)}$.

Conclusion: Intravitreal injection of trimacinolone acetonide may transiently stabilize or improve visual acuity in some patients with progressive neovascular age related macular degeneration. Intravitreal injection of bevacizumab led to a more visual improvement than IVTA in treatment CNVs. MFERG had an important role in describing the effect of treatment on retinal function. Intravitreal injection improved MFERG macular function responses with little insignificant change in F-ERG.
\end{abstract}

\section{Introduction}

None of the current treatment resulted in decreasing the loss of vision on the central $35^{\circ}$ of the retina. Neovascular age related macular degeneration is important cause of irreversible severe decrease of vision and of legal blindness in the world [1]. Triamacinolone acetonide is one of the first drugs used for the management of age related choroidal neovascularization [2].

The effects of triamacinolone acetonide were stabilization of blood retinal barrier through decreasing the permeability and inflammation. Also, triamicinolone acetonide improves the diffusion, inhibits vascular endothelial growth factor and has antiangiogenic and antifibrotic properties [3]. There is evidence that vascular endothelial growth factor (VEGF) has a potential role in ocular neovascularization and the pathogenesis of AMD [4]. Bevacizumab is a recombinant humanized monoclonal antibody to human vascular endothelium growth factor (VEGF) that binds to VEGF and blocks it from binding to its receptors [5].

Electrophysiological investigation of neovascular macular degeneration provides information of the safety of treatment. MFERG represents the photopic retinal response to a rapidly changing stimulus on the central $35^{\circ}$ of the retina [6]. Neovascular age related macular degeneration affects the central amplitude which is altered in the presence of subretinal fluid [7].MF-ERG is used to assess localized effect after treatment.

Full field ERG response reflects general retinal electrical response. Because the macula is only a small part of the retinal surface, changes in macular function even in sever neovascular age related macular degeneration are not reflected as F-ERG changes. But, global worsening of F-ERG response indicates retinal toxicity, so, F-ERG technique gives important informations of retinal toxicity with treatment.

The aim of the study was to evaluate and compare the effects of

Correspondence to: Mona Abdel Kader, Ophthalmology Center, Faculty of Medicine, Mansoura University, Mansoura, Egypt, Tel: 002-050-2202064, 01006278757; Fax: 002-050-2256104; E-mail: monaabdelkader78@yahoo.com

Key words: electroretinogram, optical coherence tomography, choroid neovascularization, avastin, triamacinolone acetate

Received: January 24, 2017; Accepted: February 10, 2017; Published: February 14, 2017 
triamacinolone acetonide and bevacizumab on vision and foveal thickness in neovascular age related macular degeneration patients and to study the effects of triamacinolone acetonide and bevacizumab on the electrophysiologic response.

\section{Subjects and methods}

This study was carried out on patients attending the Outpatient's Clinic of Mansoura Ophthalmic Center during the period from February 2013 to December 2015. This study included one hundred and fifty patients (150) with neovascular age related macular degeneration.

The patients were divided into three groups: Group 1 included patients with progressive occult or predominately occult subfoveal choroidal neovascularization who received intravitreal injection of triamcinolone acetonide, group 2 included patients with occult or predominately occult subfoveal choroidal neovascularization who received intravitreal injection of bevacizumab and group 3 (control group) included patients with neovascular age related macular degeneration but did not receive intravitreal injection for this disease. The reason for including these patients to control group was that they did not want an intravitreal injection and they refused injection after explanation the importance of injection.

Patients were thoroughly informed about the injection procedure, postoperative results and possible complications and written consents were taken from all patients. All patients were carried out in accordance with the tenets of the Declaration of Helsinki (1989) of the world medical association. The study was approved by Mansoura University Hospital trust ethics committee.

Exclusion criteria: included patients with classic type of neovascular age related macular degeneration, glaucoma, cataract surgery, retinal or vitreoretinal surgery. Sub-retinal hemorrhage should not have extended beyond the temporal vascular arcade. All patients were to be re-examined at the first postoperative day, in first postoperative week, then at monthly intervals for 6 months. A repeated injection was performed if there were signs of choroidal neovascularization (CNV) activity. Signs of CNVs activity included intra-retinal and sub-retinal fluid accumulation, new intra-retinal and sub-retinal hemorrhage and CNVs growth. The presence of signs of CNV activity and decreasing visual acuity were warranted to re-treatment.

At baseline of the study and at monthly intervals, all patients underwent a routine ophthalmological examination including visual acuity measurement using Snellen charts (Snellen acuities were converted to logarithm of the minimum angle of resolution ( $\mathrm{Log}$ MAR), slit lamp biomicroscopy, Goldman applanation tonometry, ophthalmology (direct and indirect), optical coherence tomography (OCT), electroretinogram (ERG).

Fluorescein angiography was done using Topcon Corporation 2000, TRC, 50Ix, Japan. Fluorescein angiography performed for all patients (at baseline, 3months, 6 months) showed neovascular age related macular degeneration. The membrane was occult.

\section{Optical coherence tomography (OCT)}

OCT was performed with Topcon, 3 dimensional OCT-1000 (Topcon Corporation, Tokyo, Japan). Internal fixation (subject fixated with the eye being tested) was chosen because of better reproducibility. It scanned a cube of $6 \times 6 \mathrm{~mm}$ length at resolution of $512 \times 128$ with fixation at the macula. A Measurement of macular thickness was done using the fast scan. Central macular thickness of a circular 1-mm radius area around the fovea was calculated. The print out included thickness map and the cross-sectional scan that shows morphological changes before and after intravitreal injection.

\section{ERG}

Full field ERG and MF-ERG were recorded using Roland Consult, Brandenburg, and Germany system Roland. ERG was done according to ISCEV standard [8]. After topical corneal anesthesia (Benoxinate hydrochloride 4\%), Dawson, Trick and litzkow (DTL) electrode (positive electrode) was placed just contact with corneal limbus, ground electrode was installed on the forehead and negative electrode was placed near orbital rim temporary. The recording was monocular and contra-lateral eye was occluded with light pressure to suppress blinking.

\section{Full field ERG}

The test was started and recorded in 5 steps: scotopic rod response, scotopic combined response, oscillatory potential then light adaptation for 10 minute then photopic cone response and flicker response recording.

\section{MF-ERG}

Patients were positioned $30 \mathrm{~cm}$ from the stimulus monitor. Stimulus clarity was adjusted by over-refraction. White hexagons had a luminance of 185 to $200 \mathrm{~cd} / \mathrm{m}^{2}$ and dark frames were 1 to 2 $\mathrm{cd} / \mathrm{m}^{2}$ resulting in local contrasts of $98 \%$ to $99 \%$. Each hexagon was temporally modulated between light and dark according to binary m-squence, $[9,10]$ at any time, approximately $50 \%$ of the stimulus are white and $50 \%$ are black. Patients fixated a spot in the center of the stimulus. To improve fixation stability, the sessions were divided into 30 second periods with brief rest periods. The results of two 8-minute recordings were averaged to improve the signal to noise ratio.

\section{Intravitreal injection of triamacinolone acetonide (IVTA)}

All patients in group1 received Intravitreal injection of $25 \mathrm{mg}$ of crystalline triamacinolone acetonide (Volona A; Bristol-Myers-Squibb, Munich, Germany, containing $40 \mathrm{mg}$ of triamacinolone acetonide in 1 $\mathrm{ml}$ ). The injection of $25 \mathrm{mg}$ of crystalline triamacinolone acetonide was performed using sharp 27-gauge needle in inferio-temporal quadrant $3.5 \mathrm{~mm}$ from limbus (The crystals were concentrate before injection and the triamacinolone was washed and vehicle removed). Then antibiotic ointment was applied.

\section{Intravitreal injection of bevacizumab}

All patients in group2 received Intravitreal injection of 1.25 $\mathrm{mg} / 0.05$ of bevacizumab. A total of $0.05 \mathrm{ml}$ Bevacizumab was injected into vitrous cavity $3.5 \mathrm{~mm}$ from limbus in inferotemporal quadrant using 30 gauge needle. Postoperative antibiotics were used and a light patch was placed. The eye patch is removed the next day.

\section{Statistical analysis}

Statistical analysis was performed using software (SPSS WIN Version11.5; SPSS Inc, Chicago). Non parametric Wilcoxon test was applied for comparison. Spearman rank test and linear correlation analysis were used in order to evaluate the correlation with changes of MFERG, changes of OCT and best correct visual acuity. Significance was set at $\mathrm{p}=0.05$ (2-tailed) for all statistical tests

\section{Results}


The study included one hundred and fifty (150) patients (one hundred and fifty eyes). The patients were divided into three groups: Group 1 included fifty eyes (50) of fifty patients (50) with progressive occult or predominately occult subfoveal choroidal neovascularization who received one or more than one of intravitreal injection of $25 \mathrm{mg}$ of triamcinolone acetonide, Mean age was $60 \pm 8.6$ years, ranged (5575 years old). Group 2 included another fifty eyes (50) of fifty patients with progressive occult or predominately occult subfoveal choroidal neovascularization) who received one or more than one of intravitreal injection of $\mathbf{1 . 2 5} \mathbf{~ m g / 0 . 0 5 ~} \mathbf{~ m l}$ of bevacizumab. The Mean age was $62 \pm$ 6.9 years, ranged (58-74 years).

Group 3 (Control group) included fifty eyes (50) of fifty patients (50) (with neovascular age related macular but did not receive intravitreal injection of triamcinolone acetonide for this disease after explanation the importance of treatment for visual acuity and progression of CNVs. The Mean age was $61 \pm 7.9$ years, ranged (58-74 years). There was no significant difference between groups. In group 1 , Ten (10) patients received a second intravitreal injection of $25 \mathrm{mg}$ of triamcinolone acetonide.

According to flourescein angiography, group 1 were further divided into subgroups with occult or mostly $(>50 \%)$ occult without hemorrhage $(\mathrm{n}=40,80 \%)$, subgroup with sub-retinal hemorrhage $(\mathrm{n}=7,14 \%)$ and subgroups with retinal pigment detachment $(\mathrm{n}=4,8 \%)$. While in group 2 ,occult CNV without haemorrhage was presented in 35 eyes (70\%), with haemorrhage was present in 10 eyes $(20 \%)$ and retinal pigment detachment was found in 5 eyes (10\%) (Table 1).

All three subgroups did not vary significantly $(\mathrm{p}=0.2)$ at baseline. In control group, all subjects were had occult $\mathrm{CNV}$ without subretinal hemorrhage.

\section{Visual acuity (VA)}

All patients complained of decreased vision which were diagnosed by ophthalmologic examination within three months before IVTA. The mean VA at baseline in group 1, group 2 and control group $(0.12$ $\pm 0.19,0.13 \pm 0.05$ and $0.14 \pm 0.22$ ) respectively. Range from finger counting to 0.3 in group 1 , from finger count to 0.32 in group 2 and from finger counting to 0.5 in control group.

For the group 1 and 2, mean VA increased significantly $(\mathrm{p}=0.003)$ after first injection to maximum $0.35 \pm 0.25$ during the follow up period (Table 2). The maximum postoperative VA was detected 1-2 months after the injection. The increase in VA was statistically significant in $1^{\text {st }}$ month $(\mathrm{p}=0.003)$ and $2^{\text {nd }}$ month $(\mathrm{p}=0.004)$ after the injection. The preoperative visual acuity and postoperative visual acuity achieved at the end of the follow up period did not differ significantly $(\mathrm{p}=0.2)$ in group 1 while in group 2, there is statistically significant difference between VA at the baseline and VA at the end. In group 1, Visual acuity significantly decreased towards the end of the follow up period, parallel to a disappearance of triamacinolone acetate crystals out of vitreous cavity. In group 1, after 1 month, 40 eyes (80\%) gained in visual acuity and 4 eyes (8\%) lost visual acuity. Visual acuity was unchanged for 6 eyes (12\%). While, in group 2, 45 eyes (90\%) gained in visual acuity. There was no significant correlation between postoperative visual acuity and postoperative change in visual acuity $(\mathrm{p}=0.6)$. For three subgroups, there were significant difference in gain in visual acuity $(\mathrm{p}=0.04)$. Ten eyes received second injection three months after first injection, visual acuity increased in eight eyes about one month after the re-injection and declined again after about 3 month in group 1 while in group 2, fifteen eyes received second injection after 2 months, and fourteen eyes of fifteen improved after reinjection.

\section{OCT}

For group 1, Central subfield OCT thickness was $325 \pm 50 \mu \mathrm{m}$ at baseline. The central subfield OCT thickness decreased to $280 \pm 55 \mu \mathrm{m}$ at one week and $275 \pm 40 \mu \mathrm{m}$ at one month (Table 3 , Figure 1). In group 2 , central subfield OCT thickness was $320 \pm 53 \mu \mathrm{m}$ at baseline. The Central subfield OCT thickness decreased to $270 \pm 40 \mu \mathrm{m}$ at one week and $255 \pm 41 \mu \mathrm{m}$ at one month

\section{ERG}

F-ERG data is presented in (Table 4). No significant worsening of F-ERG response was observed during follow up period in the three groups. Most of the values were within the limits normal variation which did not exceed $20 \%$ of baseline value. Grover et al said that up to $50 \%$ change in amplitude for voltage is considered normal variation [11].

For most subjects retested one month with F-ERG, the amplitude returned to baseline after a slight decrease in scotopic and photopic amplitudes at one week. For all subjects who was received either

Table 1. Evaluation of lesion element.

\begin{tabular}{|c|c|c|c|c|c|c|c|c|}
\hline \multicolumn{2}{|c|}{ CNV lesion element } & \multicolumn{2}{|c|}{ Group 1} & \multirow[b]{2}{*}{ Unchanged } & \multirow[b]{2}{*}{ Baseline } & \multicolumn{2}{|c|}{ Group 2} & \multirow[b]{2}{*}{ Unchanged } \\
\hline & Baseline & Decreased & Increased & & & Decreased & Increased & \\
\hline $\mathrm{CNV}$ & 50 & $40(80 \%)$ & $5(10 \%)$ & $5(10 \%)$ & 50 & $44(88 \%)$ & $1(2 \%)$ & $5(10 \%)$ \\
\hline FA leakage & 50 & 40 & 1 & 9 & 50 & 50 & - & - \\
\hline RPED & 4 & 3 & - & 1 & 5 & 3 & -- & 2 \\
\hline Subretinal Hge & 7 & - & - & 3 & 10 & 8 & - & 2 \\
\hline $\begin{array}{l}\text { Subretinal } \\
\text { Fluid }\end{array}$ & 30 & 20 & 2 & 8 & 25 & 23 & 1 & 1 \\
\hline
\end{tabular}

Table 2. Visual acuity among groups.

\begin{tabular}{|c|c|c|c|}
\hline Time & Group 1 & Group 2 & Group 3 \\
\hline At baseline & $0.12 \pm 0.19$ & $0.13 \pm 0.05$ & $0.15 \pm 0.22$ \\
\hline 1 week after first IVTA & $0.17 \pm 0.16$ & $18.8 \pm 0.22$ & $0.15 \pm 0.10$ \\
\hline 1 month & $0.35 \pm 0.25$ & $0.40 \pm 0.28$ & $0.15 \pm 0.19$ \\
\hline 2 month & $0.33 \pm 0.19$ & $0.38 \pm 0.21$ & $0.19 \pm 0.18$ \\
\hline 4 month & $0.25 \pm 0.15$ & $0.32 \pm 0.19$ & $0.14 .5 \pm 0.17$ \\
\hline 5 month & $0.20 \pm 0.15$ & $0.26 .5 \pm 0.1$ & $0.14 \pm 0.15$ \\
\hline
\end{tabular}


Table 3. OCT Findings of central macular thickness in $\mu \mathrm{m}$.

\begin{tabular}{|l|l|l|l|l|}
\hline $\begin{array}{l}\text { OCT (central 1 mm } \\
\text { thickness) }\end{array}$ & $\begin{array}{l}\text { Group 1 } \\
\text { After First injection }\end{array}$ & Group 2 & Control group & P \\
\hline Pre- injection & $325 \pm 50$ & $320 \pm 53$ & $315 \pm 25$ & 0.8 \\
\hline 1 week & $280 \pm 55$ & $270 \pm 40$ & $317 \pm 27$ & 0.01 \\
\hline 1 month & $275 \pm 40$ & $255 \pm 41$ & $316 \pm 29$ & 0.001 \\
\hline 2 month & $274 \pm 45$ & $240 \pm 39$ & $317 \pm 26$ & 0.01 \\
\hline 3 month & $274 \pm 40$ & $240 \pm 40$ & $319 \pm 26$ & 0.01 \\
\hline 4 month & $290 \pm 50$ & $250 \pm 30$ & $320 \pm 30$ & 0.01 \\
\hline 5 month & $310 \pm 55$ & $260 \pm 50$ & $325 \pm 29$ & 0.06 \\
\hline 6 month & $315 \pm 49$ & $266 \pm 55$ & $325 \pm 25$ & 0.02 \\
\hline
\end{tabular}

a

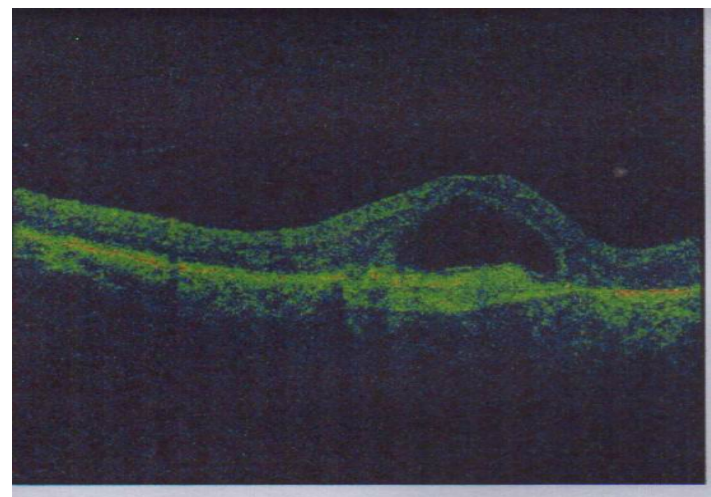

b.

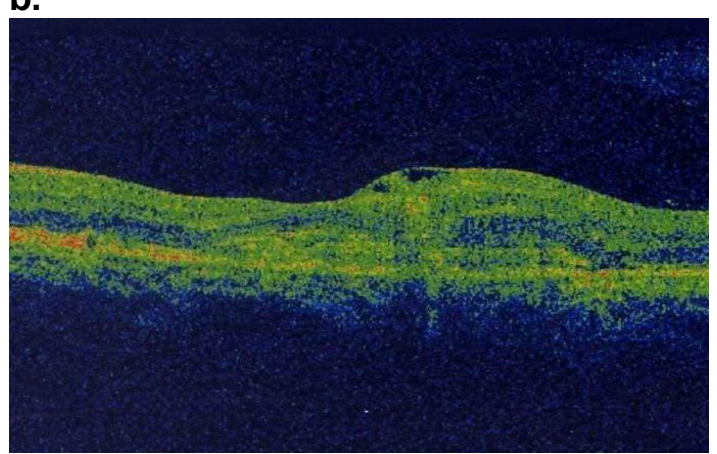

C

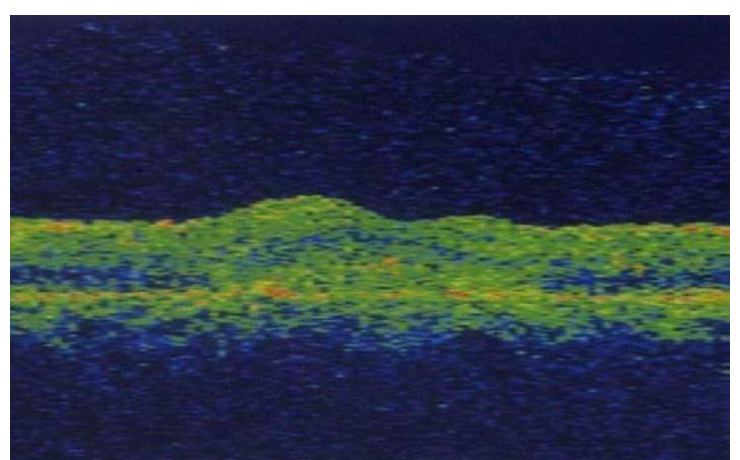

Figure 1. CNVs before and after IV injection in group 1. a. CNVs with PED before injection. b. CNVs after 1month of injection. c. CNVs after 2 month of injection.

trimacinolone acetate or bevacizumab had an essentially stable F-ERG.

\section{MFERG}

In most cases, there was improvement at one week, one month and two months of IVTA, then return to baseline value at 3 months (Table 5, Figures a

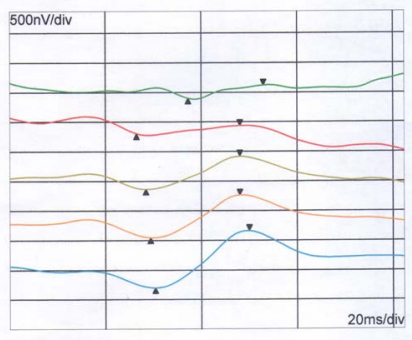

c

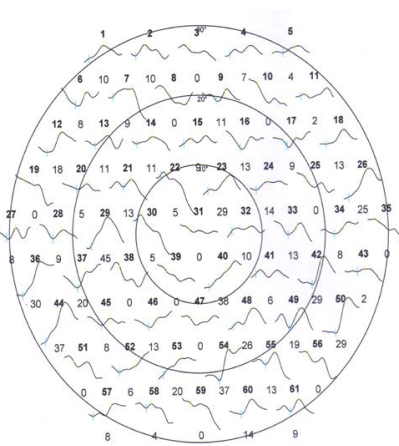

b

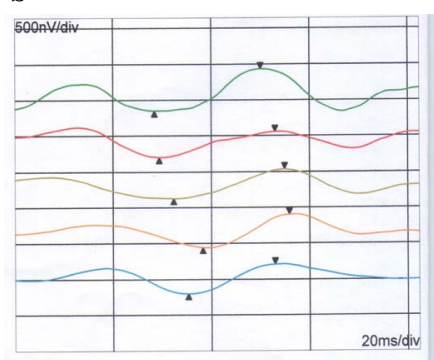

d

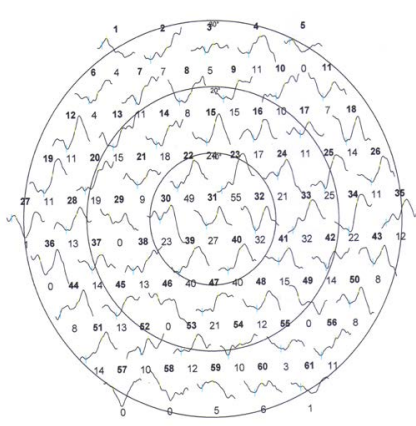

2 and 3). In group 2, there is increase in amplitude and decrease in latency reach maximum after 2 months.

\section{Intraocular complications}

In group 1 , IOP increased significantly $(\mathrm{p}=0.005)$ from $14.5 \pm 2.5$ $\mathrm{mmHg}$ at baseline of the study to a mean maximal value of $20 \pm 5.6$ $\mathrm{mmHg}$ again decreased significantly to $16.5 \mathrm{mmHg}$ at 6 months after IVTA at $p=0.001$. IOP measurements at the end were slightly and significantly $(\mathrm{P}=0.05)$ higher than pressure measurements at baseline of the study. During the study, IOP was higher than $22 \mathrm{mmHg}$ in 30 eyes $(60 \%)$.

In those patients, IOP normalized by topical anti-glaucomatous drugs. Optic nerve damage was not detected. While in group 2, there was no case with increase in intraocular pressure. With respect to other complication of IVTA, none of the patients had cortisone crystals settled on the macular region. The crystals were pre-retinally at 6 o'clock position and did not interfere with visual acuity.

Three cases of cataract were detected in group 1, while no case of cataract was observed in case 2. No postoperative infectious endophthalimitis, rhegmatogenous retinal detachment or proliferative vitreo-retinopathy were detected in groups 1 and 2.

\section{Discussion}

While, classic type of subfoveal neovascularization, photodynamic therapy with verteporfin stabilizes or increases visual acuity. Photodynamic therapy for occult subfoveal neovascularization is unsuccessful [12]. Steroids have anti-inflammatory, antiangiogenic, antifibrotic and antipermeability properties, which contribute to stabilization of the blood- retina barrier [13].

Penfold et al. [14,15], Challa et al. [16] injected trimacinolone intraviteal to treat exudative age related macular degeneration. Additionally, Danis et al. [17] detected a beneficial effect of trimacinolone in the study group compared with control group. Also, Ranson et al. [18] treated recurring subfoveal choroidal neovascularization after 
Table 4. Ganzfeld ERG in group 1 and group 2.

\begin{tabular}{|c|c|c|c|c|c|c|c|c|}
\hline ERG in group1 & baseline & 1 week & 1 month & 2 month & 3 month & 4 month & 5 month & 6 month \\
\hline \multicolumn{9}{|l|}{ Scotopic } \\
\hline Amplitude b-wave $(\mu \mathrm{v})$ & $40 \pm 9.9$ & $37 \pm 8.8$ & $40 \pm 9.9$ & $40.9 \pm 9.9$ & $40.3 \pm 9.9$ & $40.5 \pm 9.9$ & $40 \pm 9.5$ & $41 \pm 9.7$ \\
\hline Latency b-wave(ms) & $67 \pm 3.4$ & $69 \pm 4.5$ & $67 \pm 3.4$ & $67 \pm 3.4$ & $67 \pm 3.4$ & $67 \pm 3.4$ & $67 \pm 3.4$ & $67 \pm 3.4$ \\
\hline \multicolumn{9}{|l|}{ Combined } \\
\hline $\mathrm{b}$-amplitude $(\mu \mathrm{v})$ & $105 \pm 37.9$ & $100 \pm 38$ & $105 \pm 37.9$ & $105 \pm 37.9$ & $105 \pm 37.9$ & $105 \pm 37.9$ & $105 \pm 37.9$ & $105 \pm 37.9$ \\
\hline b-latency (ms) & $75 \pm 4.9$ & $77 \pm 5$ & $75 \pm 4.92$ & $75 \pm 4.93$ & $75 \pm 4.99$ & $75 \pm 4.94$ & $75 \pm 4.95$ & $75 \pm 4.9$ \\
\hline \multicolumn{9}{|l|}{ Oscillatory potential } \\
\hline amplitude( $\mu \mathrm{v})$ & $12 \pm 5.5$ & $10 \pm 5.6$ & $12.8 \pm 5.5$ & $12.89 \pm 5.5$ & $12 \pm 5.95$ & $12 \pm 5.75$ & $12 \pm 5.5$ & $12 \pm 5.5$ \\
\hline latency(ms) & $35 \pm 4.5$ & $37 \pm 5.5$ & $35.9 \pm 4.5$ & $35.77 \pm 4.57$ & $36.5 \pm 4.5$ & $37.75 \pm 4.5$ & $36.95 \pm 4.5$ & $35 \pm 4.5$ \\
\hline \multicolumn{9}{|l|}{ Flicker } \\
\hline Amplitude $(\mu v)$ & $35 \pm 8.1$ & $33 \pm 6.1$ & $35.9 \pm 8.1$ & $35.9 \pm 8.91$ & $35 \pm 8.71$ & $36.5 \pm 8.1$ & $36.85 \pm 8.1$ & $35 \pm 8.1$ \\
\hline Latency $(\mathrm{ms})$ & $72 \pm 2.5$ & $75 \pm 2.5$ & $72 \pm 2.51$ & $72 \pm 2$ & $72.6 \pm 2.5$ & $72.9 \pm 2.5$ & $72 \pm 2.95$ & $72 \pm 2.5$ \\
\hline \multicolumn{9}{|l|}{ Photopic } \\
\hline Amplitude $(\mu \mathrm{v})$ & $25 \pm 6.5$ & $23 \pm 3.9$ & $25.9 \pm 6.5$ & $25.8 \pm 6.5$ & $25 \pm 5$ & $25.1 \pm 6$ & $25 \pm 6$ & $25 \pm 6.5$ \\
\hline Latency(ms) & $37 \pm 4.5$ & $38 \pm 4.9$ & $35 \pm 4.3$ & $37.1 \pm 4.5$ & $37.7 \pm 4.5$ & $36.7 \pm 4.5$ & $36.87 \pm 4.5$ & $37 \pm 4.5$ \\
\hline ERG in group 2 & baseline & 1 week & 1 month & 2 month & 3 month & 4 month & 5 month & 6 month \\
\hline \multicolumn{9}{|l|}{ Scotopic } \\
\hline Amplitude b-wave $(\mu \mathrm{v})$ & $41 \pm 8.9$ & $36 \pm 8.8$ & $44 \pm 9.1$ & $44.9 \pm 9.9$ & $40.3 \pm 9.9$ & $40.5 \pm 9.9$ & $40 \pm 9.5$ & $41 \pm 9.7$ \\
\hline Latency b-wave(ms) & $66 \pm 3.4$ & $68 \pm 4.2$ & $65 \pm 3.1$ & $65 \pm 3.4$ & $67 \pm 3.4$ & $67 \pm 3.4$ & $67 \pm 3.4$ & $67 \pm 3.4$ \\
\hline \multicolumn{9}{|l|}{ Combined } \\
\hline $\mathrm{b}$-amplitude $(\mu \mathrm{v})$ & $106 \pm 36.9$ & $96 \pm 30$ & $115 \pm 34.9$ & $115 \pm 37.9$ & $110 \pm 37.9$ & $109 \pm 37.9$ & $108 \pm 37.9$ & $109 \pm 37.9$ \\
\hline b-latency(ms) & $74 \pm 4.5$ & $74 \pm 3.5$ & $72 \pm 4.5$ & $72.7 \pm 4.93$ & $72.5 \pm 4.99$ & $73.5 \pm 4.94$ & $73 \pm 4.95$ & $73 \pm 4.9$ \\
\hline \multicolumn{9}{|l|}{ Oscillatory potential } \\
\hline amplitude( $\mu \mathrm{v})$ & $11 \pm 5.2$ & $12 \pm 5.6$ & $13.8 \pm 5.9$ & $13.89 \pm 5.5$ & $13.2 \pm 5.95$ & $12.9 \pm 5.75$ & $13.2 \pm 5.5$ & $12.8 \pm 5.5$ \\
\hline latency(ms) & $33 \pm 4.55$ & $33 \pm 5.5$ & $32.9 \pm 4.5$ & $32.77 \pm 4.57$ & $33.5 \pm 4.5$ & $33.75 \pm 4.5$ & $34.95 \pm 4.5$ & $34.5 \pm 4.5$ \\
\hline \multicolumn{9}{|l|}{ Flicker } \\
\hline Amplitude $(\mu v)$ & $32 \pm 7.1$ & $36 \pm 6.8$ & $35.9 \pm 8.1$ & $35.9 \pm 8.91$ & $35 \pm 8.71$ & $36.5 \pm 8.1$ & $36.85 \pm 8.1$ & $35 \pm 8.1$ \\
\hline Latency $(\mathrm{ms})$ & $70 \pm 2.5$ & $69 \pm 2.3$ & $65 \pm 2.3$ & $65.8 \pm 2$ & $70.6 \pm 2.5$ & $70.9 \pm 2.5$ & $71 \pm 2.95$ & $70 \pm 2.5$ \\
\hline \multicolumn{9}{|l|}{ Photopic } \\
\hline Amplitude $(\mu \mathrm{v})$ & $23 \pm 6.5$ & $27 \pm 3.9$ & $29.9 \pm 6.5$ & $25.8 \pm 6.5$ & $26 \pm 5$ & $25.61 \pm 6$ & $26.5 \pm 6$ & $26.5 \pm 6.5$ \\
\hline Latency $(\mathrm{ms})$ & $38 \pm 4.5$ & $33 \pm 4.9$ & $32 \pm 4.3$ & $33.1 \pm 4.5$ & $33.7 \pm 4.5$ & $34.67 \pm 4.5$ & $34.78 \pm 4.5$ & $34.7 \pm 4.5$ \\
\hline
\end{tabular}

Table 5: MFERG among groups over central region.

\begin{tabular}{|c|c|c|c|c|c|c|c|}
\hline \multirow[t]{2}{*}{ Duration } & \multicolumn{2}{|c|}{ Group1 } & \multicolumn{2}{|c|}{ Group2 } & \multicolumn{2}{|c|}{ Group3 } & \multirow[t]{2}{*}{$\mathbf{P}$} \\
\hline & Amplitude & latency & Amplitude & Latency & Amplitude & latency & \\
\hline Baseline & $25.5 \pm 5.8$ & $66 \pm 6.7$ & $26.6 \pm 6.1$ & $66.5 \pm 4.9$ & $26 \pm 5.9$ & $66.5 \pm 5.9$ & 0.1 \\
\hline 1 week & $26 \pm 6.8$ & $63 \pm 4.9$ & $30 \pm 6.5$ & $62.8 \pm 5.9$ & $26.1 \pm 6.2$ & $66.3 \pm 6.1$ & 0.1 \\
\hline 1 month & $31 \pm 8.9$ & $59 \pm 5.6$ & $33 \pm 9.9$ & $55.1 \pm 4.5$ & $26.5 \pm 6.1$ & $65.9 \pm 6.5$ & 0.001 \\
\hline 2 month & $35 \pm 7.3$ & $55 \pm 4.8$ & $35 \pm 8.7$ & $53 \pm 4.1$ & $25 \pm 5.8$ & $66 \pm 6.1$ & 0.001 \\
\hline 3 month & $32 \pm 3.1$ & $56.5 \pm 4.1$ & $31 \pm 5.5$ & $51 \pm 4.2$ & $25.3 \pm 6.6$ & $67 \pm 6.8$ & 0.01 \\
\hline 4 month & $27 \pm 4.6$ & $59 \pm 4.6$ & $30.5 \pm 4.5$ & $52.5 \pm 5$ & $26.4 \pm 6.4$ & $67 \pm 6.1$ & 0.2 \\
\hline 5 month & $26 \pm 5.6$ & $65 \pm 5.1$ & $30 \pm 3.9$ & $54 \pm 4.5$ & $24.5 \pm 6.5$ & $67 \pm 6.5$ & 0.05 \\
\hline 6 month & $26 \pm 5.6$ & $65 \pm 5.2$ & $30 \pm 4.7$ & $55 \pm 5.2$ & $24 \pm 5.5$ & $67 \pm 6.5$ & 0.04 \\
\hline
\end{tabular}

laser treatment by IVTA.

Challa et al. [16] evaluated the safety and efficacy of intravitreal of trimacinolone after one and half year of follow up in exudative age related macular degeneration considered unsuitable for laser photocoagulation. They reported that a single intravitreal injection of 4 $\mathrm{mg}$ of trimacinolone acetate was well tolerated and helpful in treatment of exudative age related macular degeneration.

In this study (in group 1), there was increase in visual acuity, reduction of fluorescein angiography leakage, reduction central macular thickness and increase in amplitude of MFERG with reduction of implicit time in 40 eyes of 50 eyes (80\%) within 2 months. Ten eyes of 40 eyes (25\%) receive another intravitreal injection after 3 months (after beginning of reduction of visual acuity with increase macular thickness, reduction of amplitude of MFERG and increase implicit time). There was improvement of six of ten eyes (60\%).

There was correlation between visual acuity and central macular thickness $(\mathrm{p}=0.008, \mathrm{R}=0.5)$ and visual acuity and MFERG amplitude $(\mathrm{P}=0.006, \mathrm{R}=0.55)$. Also, there was significant correlation between central macular thickness and MFERG amplitude $(\mathrm{P}=0.001, \mathrm{R}=0.65)$ in group 1.

In this study, we injected high dose of triamcinolone acetate intravitreal in group 1, because the results of previous studies were not clear; Jonas et al. $[19,20]$ found significant increase in visual acuity after intravitreal injection of $25 \mathrm{mg}$ of trimacinolone acetate. While Gillies et al. [21] reported no effect of $4 \mathrm{mg}$ of intravitreal injection of trimacinolone acetate on the development of sever visual loss over a 
a

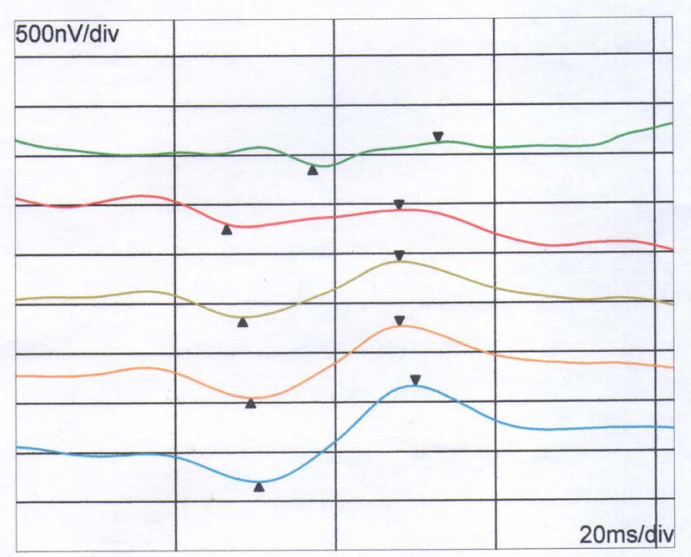

c

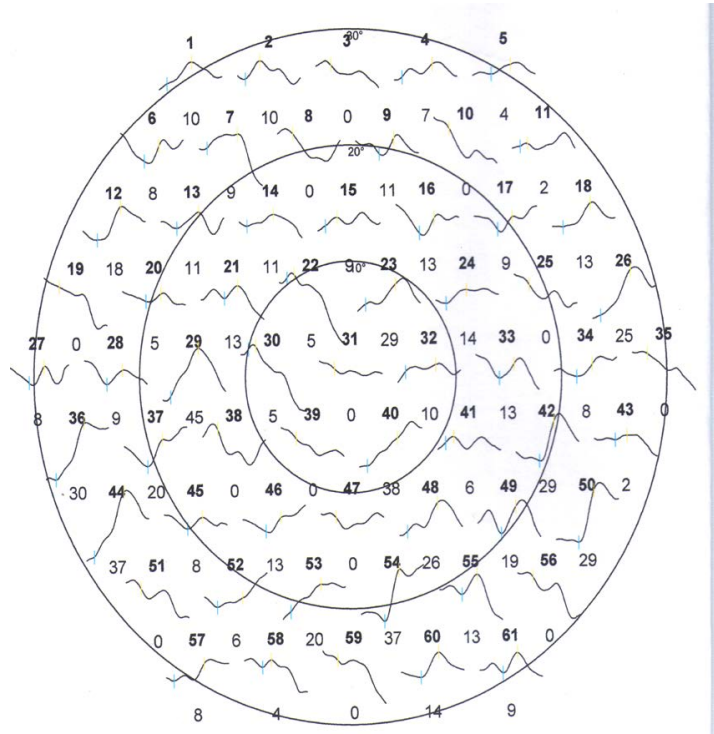

b

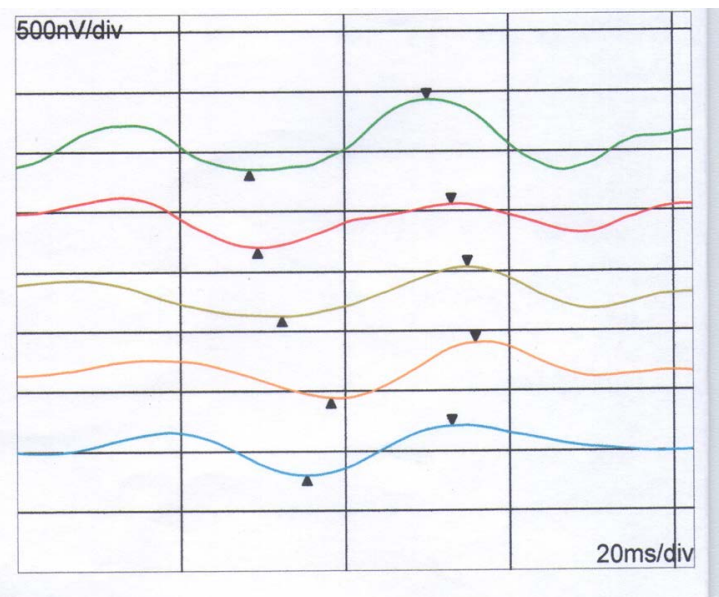

d

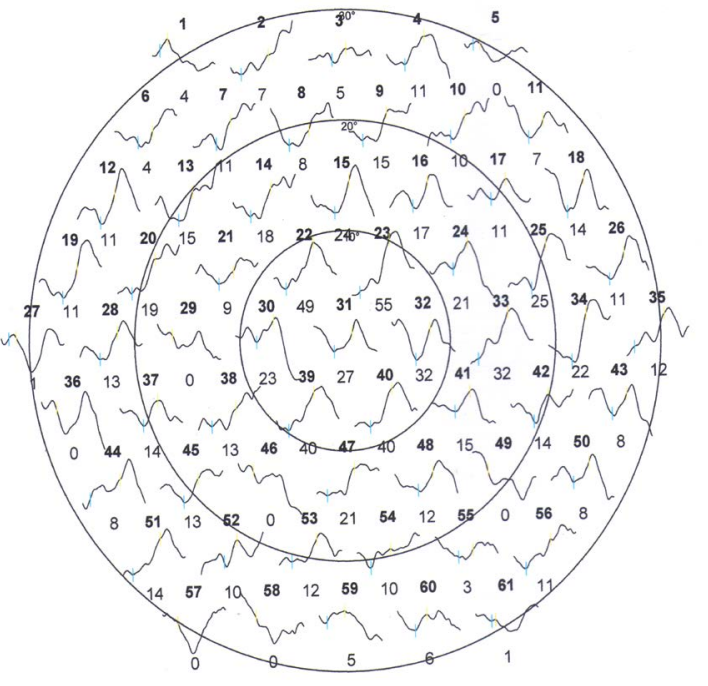

Figure 2. MFERG before and after injection in group 1. a. 5-rings of MFERG before injection. b. 5-rings of MFERG after injection. c. trace array of MFERG before injection. d. trace array of MFERG after injection.

follow up period of 1 year. The causes for the difference between studies may be the amount of injected trimacinolone acetate.

Another cause for difference between studies may be related to the effect of development of cataract on vision. An additional reason for discrepancy between this study and investigation of Gillies et al. [21] may be that their study included classic subfoveal choroidal neovascularization which is associated with a worse prognosis compared with occult choroidal neovascularization.

There was significant elevation in intraocular pressure in group1 compared with other groups. There were 30 eyes $(60 \%)$ had increased intraocular pressure. All cases were controlled with medical antiglaucomatous treatment.

Various studies have reported increase of IOP ranging from 11-30\% of subjects following IVTA $[17,19,22]$.

None of patients had been shown infectious endophthalmitis, rhgmatogenous retinal detachment, or proliferative vitreoretinopathy in this study. Regards the duration of the therapeutic effect of $25 \mathrm{mg}$ of intravitreal injection of trimacinolone acetate, Jonas et al. [18] found the reduction of visual acuity started 4-5 months after initial increase in visual acuity two months after injection.

Similarly, in the present study after initial increase of vision two month after injection, visual performance started to decrease again. This may be result from resolving of trimacinolone acetate crystals. Vascular endothelial growth factor (VEGF) plays an important role in the pathogenesis of AMD [22]. Intravitreal bevacizumab injection was reported to be effective for treatment exudative AMD. Bevacizumab inhibit VEGF, decrease angiogenesis and decrease vascular permeability [23-25].

In group 2, there were increase in visual acuity, reduction in retinal thickness and improvement of electrophysiological amplitudes and latencies. The improvement was slightly more significant in group 2 than in group1 (As seen in table 2ssss). The cause for this improvement in group 2 more than group 2 is that triamcinolone 
a

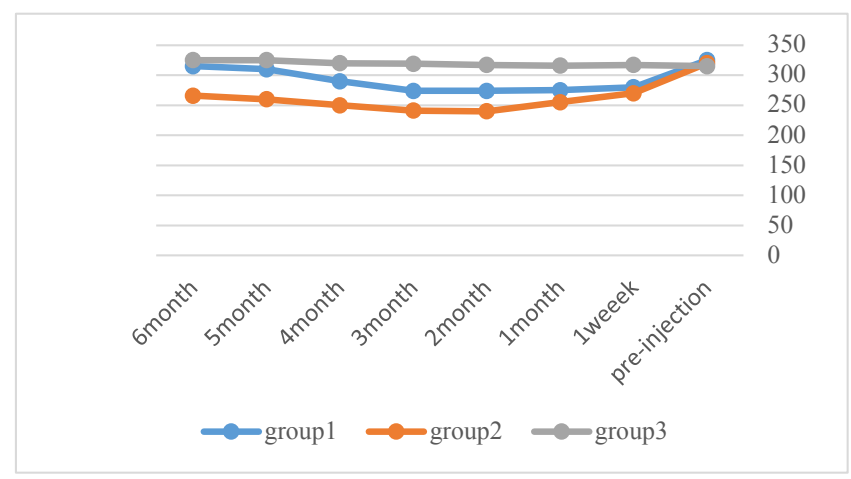

b

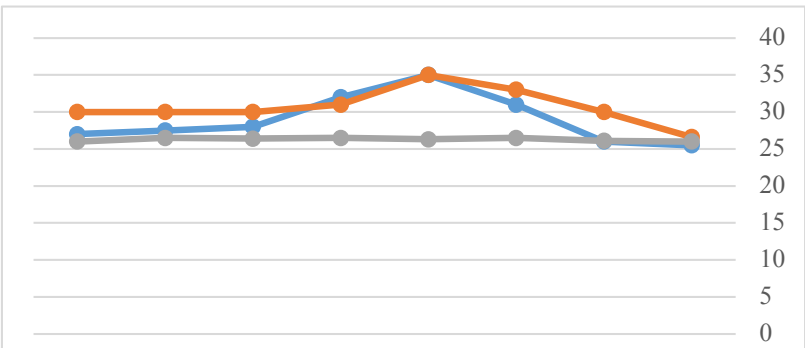

6month 5month 4month 3month 2month 1month 1week baseline

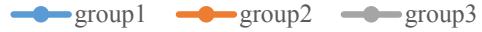

c

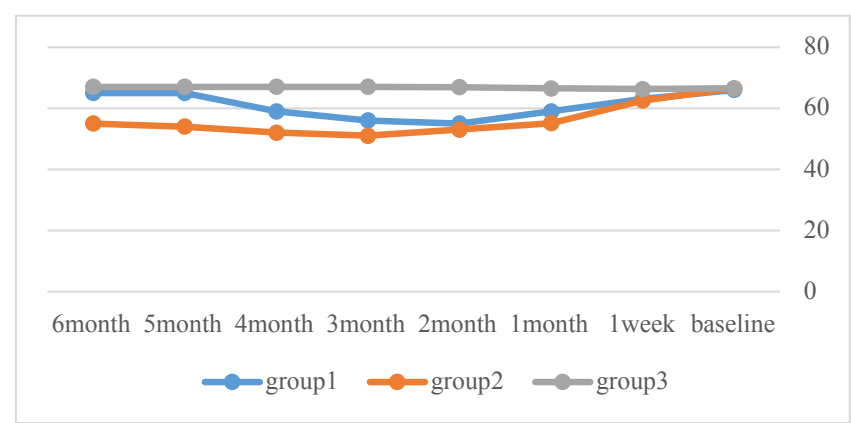

Figure 3. OCT and MFERG changes among groups. a. OCT changes among groups. b. MFERG changes of amplitudes among groups. c. MFERG changes of latencies among groups.

exerted its antiangiogenic effect by enhancing endostatin expression rather than suppressing VEGF expression [26]; While bevacizumab decrease angiogenesis by decreasing VEGF expression and enhancing endostatin [27].

There was correlation between visual acuity and central macular thickness ( $\mathrm{p}=0.006, \mathrm{R}=0.55$ ) and visual acuity and MFERG amplitude $(\mathrm{P}=0.005, \mathrm{R}=0.65)$. Also, there was significant correlation between central macular thickness and MFERG amplitude $(P=0.003, R=0.6)$ in group 2. Similarly, Rosenfeld et al reported that intravitreal injection of bevacizumab cause marked decrease in retinal thickness without toxicity [28]. Ahmadieh et al. [29] observed improvement of vision and reduction of thickness after bevacizumab.
Also, Falkenstein et al. [30] showed that primary bevacizumab therapy resulted in significantly visual improvement [30] The bevacizumab preparation is unpreserved and contains no ingredients that are toxic to the eye [28]. Intravitreal bevacizumab is well tolerated in the majority of patients. In this study, there were no complication in group 2. Only subconjuctival heamorrhage in two cases which resolved within a week.

While, Ahmadieh et al. [29] observed one case with pigment epithelial detachment without any cases of endophalmitis or subconjuctival haemorrhage. Also, Cleary et al. [30] Found endophthalmitis in 1 of 112 eyes, submacular hemorrhage in 3 of 112 eyes and retinal pigment epithelial tears in 3 of 112 eyes. Ronan et al. [31] and Avery said that the presence of pigment epithelial detachment was risk factor for retinal pigment epithelial tear after IVB injection.

The limitations of this study, were the method of measuring visual acuity. Instead of the charts used for the Early Treatment Diabetic Retinopathy [33] visual acuity was determined using Snellen charts in a standardized fashion. But, the same method for detection visual acuity was applied to three groups. Other limitation of this study was limited follow up and limited number of the patients, the relatively high dose of trimacinolone acetate injected into eye.

In summary, intravitreal injection of trimacinolone acetate and bevacizumab improve visual acuity transiently in patients with neovascular age related macular degeneration. Furthermore, intravitreal injection caused anatomical changes and functional improvement of MFERG. Bevacizumab gave more favorable visual outcome and anatomical and functional improvement than triamcinolone acetate. To stabilize visual acuity, repeated intravitreal injection is recommended with 2-3 months apart with take care of complication especially intraocular pressure in cases of IVTA.

\section{Funding}

No funding was received for this research.

\section{Conflict of interest}

All authors certify that they have NO affiliations with or involvement in any organization or entity with any financial interest (such as honoraria; educational grants; participation in speakers' bureaus; membership, employment, consultancies, stock ownership, or other equity interest; and expert testimony or patent-licensing arrangements), or non-financial interest (such as personal or professional relationships, affiliations, knowledge or beliefs) in the subject matter or materials discussed in this manuscript.

\section{Ethical approval}

All procedures performed in studies involving human participants were in accordance with the ethical standards of the institutional and/ or national research committee and with the 1964 Helsinki declaration and its later amendments or comparable ethical standards. Additional informed consent was obtained from all individual participants for whom identifying information is included in this article.

\section{References}

1. Vingerling JR, Dielemans I, Hofman A, Grobbee DE, Hijmering M, et al. (1995) The prevalence of age-related maculopathy in the Rotterdam Study. Ophthalmology102: 205-210.[Crossref]

2. Becerra E, Morescalchi F, Gandolfo F, Danzi P, Nascimbeni G, et al. (2011) Clinical evidence of intravitreal triamcinolone acetonide in the management of age related macular degeneration. Curr Drug Targets 12:149-172. [Crossref] 
3. Peyman GA, Moshfeghi DM (2004) Intravitreal triamcinolone acetonide. Retina24: 488-490.[Crossref]

4. Augustin AJ, Puls S, Offermann I (2007) Triple therapy for choroidal neovascularization due to age-related macular degeneration: verteporfin PDT, bevacizumab, and dexamethasone. Retina27: 133-140.[Crossref]

5. Lüke M, Warga M, Ziemssen F, Gelisken F, Grisanti S, et al. (2006) Effects of bevacizumab on retinal function in isolated vertebrate retina. Br J Ophthalmol90: 11781182.[Crossref]

6. Maluri RK, Laura A,Bleau LPN, Donald L, Wilson M (2006) Electrophysiologic findings after intravitreal Bevacizumab (Avastin) treatment. Retina26:270-274. [Crossref]

7. Sutter EE, Tran D (1992) The field topography of ERG components in man--I. The photopic luminance response. Vision Res 32: 433-446.[Crossref]

8. Mc Culloch DL,Marmor MF, Brigell MG, Hamilton R, Holder G, et al. (2015) ISCEV Standard for full-field clinical electroretinography. Doc Ophthalmol130: 1-12. [Crossref]

9. Hood DC, Li J (1997) A Technique for measuring individual multifocal ERG records. In: Yages D, ed. Non invasiveassessment of the visual system. Trends in Optic and Photonics 11: 280-283.

10. Hood DC, Seiple W, Holopigian K, Greenstein V (1997) A comparison of the components of the multifocal and full-field ERGs. Vis Neurosci14: 533-544.[Crossref]

11. Grover S, Fishman GA, Birch DG, Locke KG, Rosner B (2003) Variability of fullfield electroretinogram responses in subjects without diffuse photoreceptor cell disease. Ophthalmology10:1159-1163. [Crossref]

12. Schimdt-Erfurth U, Miller JWS,Sickenberg M (1991) Photodynamic therapy with verteporfm for choroidal neovascularization by age related macular degeneration. Arch Ophthalmology 17:1177-1187. [Crossref]

13. Penfold PL, Gyory JF, Hunyor AB, Billson FA (1995) Exudative macular degeneration and intravitreal triamcinolone. Aust NZJ Ophthalmology 23:293-298. [Crossref]

14. Ciulla TA, Criswell MH, Danis RP (2001) Intravitreal triamcinolone acetonide inhibits choroidal neovascularization in a laser-treated rat model. Arch Ophthalmol119: 399404. [Crossref]

15. Penfold PL (2002) Intravitreal triamcinolone in recurrence of choroidal neovascularisation. Br J Ophthalmol86: 600-601.[Crossref]

16. Challa JK, Gillies MC, Penfold PL, Gyory JF, Hunyor AB, et al. (1998) Exudative macular degeneration and intravitreal triamcinolone: 18 month follow up. Aust $N Z J$ Ophthalmol26: 277-281.[Crossref]

17. Danis RP, Ciulla TA, Pratt LM, Anliker W (2000) Intravitreal triamcinolone acetonide in exudative age-related macular degeneration. Retina20: 244-250.[Crossref]

18. Ranson NT, Danis RP, Ciulla TA, Pratt LM (2002) Intravitreal trimacinolone in subfoveal recurrence of choroidal neovascularization after laser treatment in macular degeneration. Br J Ophthalmology86:527-529. [Crossref]

19. Jonas JB, Kreissig I, Hugger P, Sauder G, Panda-Jonas S, et al. (2003) Intravitreal triamcinolone acetonide for exudative age related macular degeneration. $\mathrm{Br} J$ Ophthalmol87: 462-468.[Crossref]

20. Jonas JB, Akkoyun I, Budde WM, Kreissig I, Degenring RF (2004) Intravitreal reinjection of triamcinolone for exudative age-related macular degeneration. Arch Ophthalmol122: 218-222.[Crossref]

21. Gillis MC, Lao W, Chua W (2001) The efficacy of a single intravitreal injection of trimacinolone for neovascular age related macular degeneration, One year results of randomized clinical trial IVTA. Invest Ophthalmology Vis Sci42:437-439

22. Augustin AJ, Puls S, Offermann I (2007) Triple therapy for choroidal neovascularization due to age-related macular degeneration: verteporfin PDT, bevacizumab, and dexamethasone. Retina 27: 133-140. [Crossref]

23. Wingate RJ, Beaumont PE (1999) Intravitreal triamcinolone and elevated intraocular pressure. Aust N Z J Ophthalmol27: 431-432.[Crossref]

24. van Wijngaarden P, Coster DJ, Williams KA (2005) Inhibitors of ocular neovascularization: promises and potential problems. JAMA293: 1509-1513.[Crossref]

25. Arevalo JF, Fromow-Guerra J, Sanchez JG, Maia M, Berrocal MH, et al. (2008) Primary intravitreal bevacizumab for subfoveal choroidal neovascularization in age related macular degeneration: results of the Pan-American Collaborative Retina Study Group at 12 months follow-up. Retina 28:1387-1394. [Crossref]

26. Tatar O, Shinodo K, Kaiserling E (2008) Early effects of triamcinolone on vascula endothelial growth factor and endostatin in human choroidal neovascularization. Arch Ophthalmol126: 193-199. [Crossref]

27. Tatar O, Shinoda K, Kaiserling E, Claes C, Eckardt C, et al. (2009) Implications of bevacizumab on vascular endothelial growth factor and endostatin in human choroidal neovascularisation. Br J Ophthalmol93: 159-165. [Crossref]

28. Rosenfeld PJ, Moshfeghi AA, Puliafito CA (2005) Optical coherence tomography findings after an intravitreal injection of bevacizumab (avastin) for neovascular agerelated macular degeneration. Ophthalmic Surg Lasers Imaging 36: 331-335.[Crossref]

29. Ahmadieh H, Taei R, Riazi-Esfahani M, Piri N, Homayouni M, et al. (2011) Macular degeneration intravitreal bavacizumab versus combined intravitreal bevacizumab and triamacinolone for neovascular age related. Retina31: 1819-1826. [Crossref]

30. Cleary CA, Jungkim S, Ravikumar K, Kelliher C, Acheson RW, et al. (2008) Intravitreal bevacizumab in the treatment of neovascular age-related macular degeneration, 6- and 9-month results. Eye (Lond) 22: 82-86.[Crossref]

31. Ronan SM, Yoganathan P, Chien FY, Corcóstegui IA, Blumenkranz MS, et al. (2007) Retinal pigment epithelium tears after intravitreal injection of bevacizumab (Avastin) for neovascular age-related macular degeneration. Retina27: 535-540. [Crossref]

32. Avery RL, Pieramici DJ, Rabena MD, Castellarin AA, Nasir MA, et al. (2006) Intravitreal bevacizumab (Avastin) for neovascular age-related macular degeneration. Ophthalmology113: 363-372.[Crossref]

33. Falkenstein IA, Cheng L, Morrison VL, Kozak I, Tammewar AM, et al. (2007) Standardized visual acuity results associated with primary versus secondary bevacizumab (Avastin) treatment for choroidal neovascularization in age-related macular degeneration. Retina 27: 701-706. [Crossref]

Copyright: (C2017 Kader MA. This is an open-access article distributed under the terms of the Creative Commons Attribution License, which permits unrestricted use, distribution, and reproduction in any medium, provided the original author and source are credited. 